with a liposarcoma are symptomatic and that $15 \%$ have an asymptomatic liposarcoma discovered on a routine chest radiograph. Liposarcomas are usually large. The cases reported by Klimstra and associates ${ }^{3}$ ranged from 6 to $40 \mathrm{~cm}$, with a mean weight of 1500 g. Enzinger and Weiss ${ }^{4}$ divided liposarcomas into the following 5 major morphologic subtypes: well differentiated, myxoid, round cell, dedifferentiated, and pleomorphic. Myxoid liposarcomas account for $40 \%$ to $50 \%$ of these tumors. Welldifferentiated liposarcomas are a less-aggressive neoplasm and can produce metastases. Complete surgical excision is the preferred therapeutic choice. Recurrence can occur in a subtotal resection despite adjuvant therapy. The pseudoencapsulated lesions that can be completely removed have a better prognosis than the noncapsulated and less well-differentiated tumors; however, most primary chest wall soft tissue sarcomas (70\%) are low grade. Local recurrence was reported in $33 \%$ of patients in the study by Greager and colleagues. ${ }^{5}$ The presence of local recurrence has no significant effect on the overall survival. ${ }^{1}$ Radiotherapy may be effective in the control of local recurrence, but its role is unclear.

\section{References}

1. Gordon MS, Hajdu SE, Bains MS, Burt ME. Soft tissue sarcomas of the chest wall. J Thorac Cardiovasc Surg. 1991;101:843-54.

2. Schweitzer DL, Aguam AS. Primary liposarcoma of the mediastinum. Report of a case and review of the literature. J Thorac Cardiovasc Surg. 1977;74:83-97.

3. Klimstra DS, Moran CA, Perino G, Koss MN, Rosai J. Liposarcoma of the anterior mediastinum and thymus: a clinicopathologic study of 28 cases. Am J Surg Pathol. 1995;19:782-91.

4. Enzinger FM, Weiss SW. Soft tissue tumors. 3rd ed. St Louis: CV Mosby; 1995, p. 431.

5. Greager JA, Patel MK, Briele HA, Walker MJ, Wood DK, Gupta TK. Soft tisue sarcomas of the adult thoracic wall. Cancer. 1987;59:370-3.

\title{
Cerebral malperfusion in acute type $A$ dissection: Direct innominate artery cannulation
}

Genichi Sakaguchi, MD, PhD, Tatsuhiko Komiya, MD, Nobushige Tamura, MD, PhD, Shogo Obata, MD, Shinji Masuyama, MD, Chieri Kimura, MD, and Taira Kobayashi, MD, Okayama, Japan

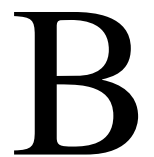

rain ischemia caused by malperfusion of major arch vessels in acute type A dissection is associated with a significantly higher risk of mortality. This report describes an urgent introduction of the selective cerebral perfusion immediately after establishment of cardiopulmonary bypass followed by total arch replacement in a case of acute type A dissection complicated with preoperative cerebral ischemia.

\section{Clinical Summary}

A 56-year-old man was transferred to our hospital after presenting with an abrupt loss of consciousness. At the time of admission, the patient was lethargic, although easily arousable, and responded to his name being called. His consciousness

\footnotetext{
From the Department of Cardiovascular Surgery, Kurashiki Central Hospital, Okayama, Japan.

Received for publication Aug 6, 2004; revisions received Sept 1, 2004; accepted for publication Sept 3, 2004.

Address for reprints: Genichi Sakaguchi, MD, Department of Cardiovascular Surgery, Kurashiki Central Hospital, Miwa, Kurashiki City, Okayama, 710-8602, Japan (E-mail: gs8722@kchnet.or.jp).

J Thorac Cardiovasc Surg 2005;129:1190-1

$0022-5223 / \$ 30.00$

Copyright (C) 2005 by The American Association for Thoracic Surgery

doi:10.1016/j.jtcvs.2004.09.036
}

level was assessed at 14 on the Glasgow Coma Scale. His initial brain

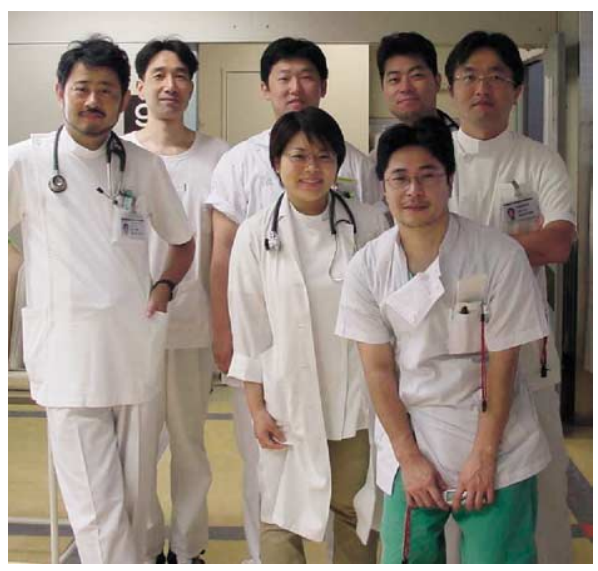

Komiya, Tamura, Masuyama, Kimura, Kobayashi, Obata, Sakaguchi (left to right) computed to-

mographic (CT)

scan disclosed neither acute hemorrhage nor obvious ischemic changes. According to the neurologic status and CT findings, it was speculated that he did not have a cerebral infarction, despite the right-sided hemispheric hypoperfusion.

Duplex ultrasonography showed compression of the true lumen by the false lumen in the right carotid artery (Figure 1). A contrastenhanced CT scan revealed a type A dissection extending from the sinotubular junction down to the bilateral common iliac arteries.

An emergency operation was performed 2 hours after admission. Near-infrared optical spectrophotometer probes were attached to the bilateral forehead of the patient to monitor regional cerebral oxygenation $\left(\mathrm{rSO}_{2}\right)$ throughout the operation (Figure 2). $\mathrm{rSO}_{2}$ in the right side of the forehead was $21 \%$, and that in the left side of the forehead was $50 \%$.

After cardiopulmonary bypass was established with the right femoral artery used for inflow and the superior and inferior venae cavae for drainage, $\mathrm{rSO}_{2}$ was still at a critically low level on the right side. The innominate artery was crossclamped proximally and transected. A $14 \mathrm{~F}$ perfusion catheter was inserted in the true 


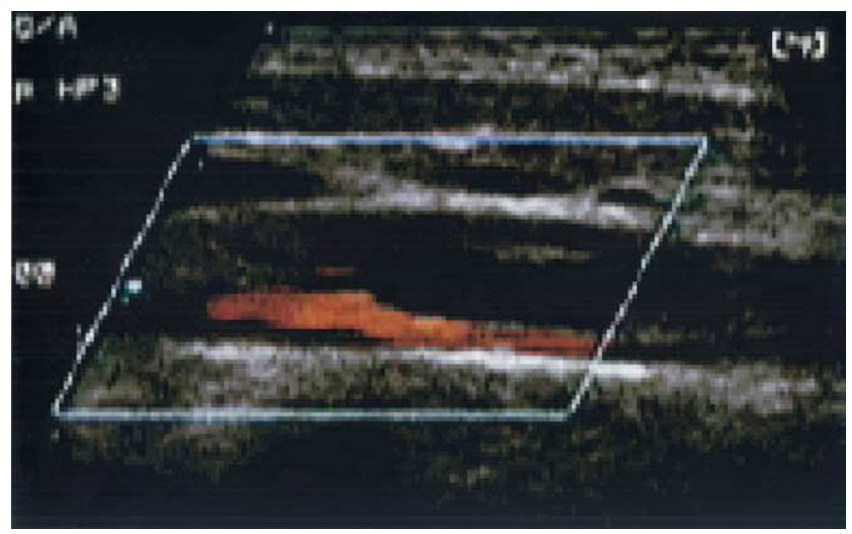

Figure 1. Duplex carotid echocardiogram showing compression of the true lumen by the false lumen in the right carotid artery.

lumen of the innominate artery, and partial selective cerebral perfusion was started. The $\mathrm{rSO}_{2}$ in the right side of the forehead immediately recovered to the level of the left side (50\%). The patient was cooled $\left(25^{\circ} \mathrm{C}\right)$, and the systemic perfusion through the femoral artery was discontinued. An intimal tear was identified in the aortic arch. Perfusion catheters were inserted in the left common carotid artery and the left subclavian artery for total cerebral perfusion. The total arch was replaced with a tube graft with 4 limbs, and selective cerebral perfusion was terminated. The patient was discharged on postoperative day 19 without any neurologic deficits.

\section{Discussion}

Preoperative neurologic deficit is highly associated with operative mortality in surgical treatment for acute type A dissection. ${ }^{1}$ Fann and colleagues ${ }^{2}$ reported that arch vessel occlusion caused stroke in $5.5 \%$ of patients with acute type A dissection. The right carotid artery is most commonly involved, and this often occurs in conjunction with innominate artery dissection. ${ }^{2}$ In our case the preoperative cerebral malperfusion resulted from extension of the dissection into the right carotid artery with compression of the true lumen. The axillary artery has been proposed as an inflow of cardiopulmonary bypass in the operation for acute type A dissection to avoid malperfusion instead of the femoral artery ${ }^{3}$; however,

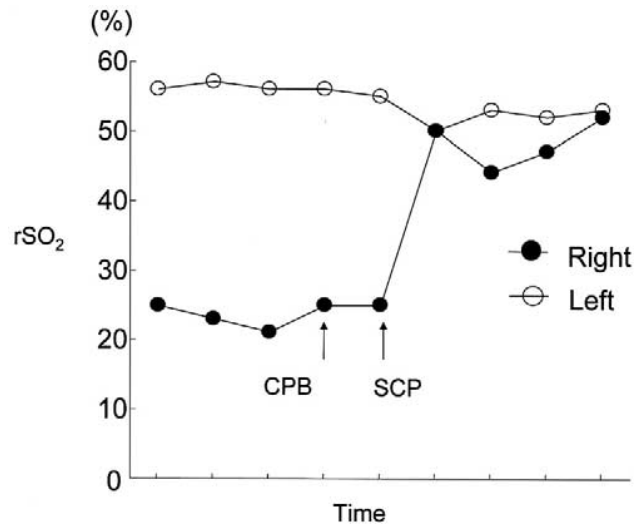

Figure 2. Changes in $\mathrm{rSO}_{2}$ during the procedure. $C P B$, Cardiopulmonary bypass; $S C P$, selective cerebral perfusion.

the direct innominate artery cannulation is a less time-consuming (easy) and reliable method to restore cerebral perfusion in such a case with cerebral malperfusion. Fukada and coworkers ${ }^{4}$ reported an intraoperative cerebral malperfusion caused by retrograde femoral perfusion that had been successfully treated in the same method.

Because it was speculated that the patient did not have cerebral infarction, despite the right-sided hemispheric hypoperfusion in this case, the more rapid restoration of cerebral perfusion was expected to result in less cerebral damage.

\section{References}

1. Pansini S, Gagliardotto PV, Pompei E, Parisi F, Bardi G, Castenetto E, et al. Early and late risk factors in surgical treatment of acute type A aortic dissection. Ann Thorac Surg. 1998;66:779-84.

2. Fann JI, Sarris GE, Miller DC, Mitchell S, Oyer PE, Stinson EB, et al. Surgical management of acute aortic dissection complicated by stroke. Circulation. 1989;80(suppl I):I257-63.

3. Sabik JF, Nemeh H, Lytle BW, Blackstone EH, Gillinov AM, Rajeswaran J, et al. Cannulation of the axillary artery with a side graft reduces morbidity. Ann Thorac Surg. 2004;77:1315-20.

4. Fukada J, Morishita K, Kawaharada N, Yamauchi A, Hasegawa T, Satsu $\mathrm{T}$, et al. Isolated cerebral perfusion for intraoperative cerebral malperfusion in type A aortic dissection. Ann Thorac Surg. 2003;75: 266-8. 